AC 2012-3762: LOOKING AHEAD: SOME TRENDS IN GRADUATE EDUCATION AND THEIR IMPACT ON ENGINEERING AND TECHNOLOGY

Prof. Joy L. Colwell, Purdue University, Calumet

Joy L. Colwell, J.D., is currently Director of Graduate Studies at Purdue University Calumet, and professor of organizational leadership and supervision. 


\title{
Looking Ahead: Some Trends in Graduate Education and Their Impact on Engineering and Technology
}

\begin{abstract}
In order to plan for and meet future needs, graduate education in engineering and technology should consider the current trends in both higher education and graduate education. In a time of economic uncertainty, planning and decision-making must be based on an awareness of the larger societal (and perhaps global) context in which they occur to ensure both the wisest allocation of scarce resources and the best preparation of students for their future careers. Higher education and graduate education are increasingly scrutinized and pushed to demonstrate value to the potential student (and possibly to the taxpayers who may provide funding to state-assisted public universities and institutions of higher education).
\end{abstract}

Some of the current trends in graduate and higher education are reviewed to help graduate programs in engineering and technology better plan for the future. Based upon a review of current information (along the lines of trend analysis or environmental scanning typically done by businesses as part of strategic planning), some trends affecting graduate education will be identified. Trends reviewed include: some long-term enrollment predictions, economic factors for institutions and students (accountability and affordability), the goals of higher education and graduate education, and demographic characteristics and their impact. Some recent research in undergraduate education will be touched upon, particularly Arum and Roksa's Academically Adrift: Limited Learning on College Campuses ${ }^{1}$, ( referred to as Academically Adrift) and examined for its potential impact on graduate education. The changes and trends affecting graduate education fall into the following themes:

- Enrollment trends; with a note on gender balance and demographics

- Cost (affordability) and accountability;

- The job market and job preparation (purpose of graduate education), and

- Rigor and student preparation for graduate study.

\section{Introduction-- The Higher Education Landscape}

In this paper, some of the current trends in graduate education are reviewed, along with an exploration of the impact of some of these trends, to help graduate programs in engineering and technology better plan for the future. These trends are identified based upon a review of currently available information and sources, along the lines of trend analysis or environmental scanning typically done by businesses as part of strategic planning. Some of the trends identified include the job market for graduates and how graduate education has traditionally prepared students for careers (which touches upon the purpose of graduate education); and economic factors for institutions and students and demographic characteristics and their impact (the topics frequently identified as accountability and affordability). Some recent research in undergraduate education is touched upon, particularly Arum and Roksa's Academically Adrift ${ }^{2}$, and examined 
for its potential impacts on graduate education. Relevant information from the newly released Council of Graduate School's publication, Graduate Enrollment and Degrees: 2000-2010 ${ }^{3}$ is also included.

The focus of trends in the higher education landscape is based on some relatively recent and rapid changes. The changes and trends affecting graduate education fall into the following themes:

- Enrollment trends; with a note on gender balance and demographics

- Cost and accountability;

- The job market and job preparation, and

- $\quad$ Rigor and undergraduate student preparation for graduate study.

\section{Trend 1: Enrollment Projections}

According to the National Center for Education Statistics (NCES), college enrollments overall are anticipated to increase through 2020, even though high school enrollments will flatten or decline slightly. ${ }^{4}$ The growth is anticipated to rise 13\% from 2009 to 2020, based on projections from the NCES' "Projections of Education Statistics Through 2020" cited above. The Council of Graduate Schools (CGS) also projects that graduate enrollments will increase as well (see discussion below). The CGS Survey of Graduate Enrollment and Degrees: 2000 to 2010 provides information based on 655 responding institutions, receiving nearly 1.77 million applicants for admission to graduate programs. ${ }^{5}$

\section{Enrollments v. Long Term Projections for Growth}

Recently, there has been a slight decline in graduate enrollments. The CGS reports that the enrollments for new students in US graduate schools declined for the first time in seven years for fall of 2010. ${ }^{6}$ Enrollment s fell by 1.1\%, despite having increased by 5.5\% from 2009 to $2010 .^{7}$ The CGS report identifies the cause for the drop in enrollments as the decline in part-time graduate enrollment. ${ }^{8}$ First time full time enrollments actually increased by $3.4 \%$, but this was offset by a decline in part-time enrollments of $8.5 \%$. Although the number of applications increased by $8.4 \%$ from $2009-2010^{9}$, the actual enrollments are down, with the continued state of the economy identified as the likely cause. It is the author's opinion that with the continued downturn in the nation's economy, employers have cut tuition reimbursement benefits, and the applicants themselves may have exhausted their funds to pursue graduate education. (The converse argument which might explain the drop is that the economy has improved, and that students who had returned to graduate studies during temporary employment layoffs have now returned to work.)

One possible explanation is that universities are facing stringent budgets with endowment losses and cuts in state support, and funds for stipends and graduate aide positions are not as available for potential graduate students. Similar comments appear in the article "Graduate Enrollment Declines in Part Because of Caution About the Economy."10 It is interesting to note that according to the CGS the decline has been for domestic applicants; international applicants have continued to rise, with a 4.7\% increase from 2009 to 2010. 
Of interest to engineering and technology-- the largest average annual increases were in health sciences, engineering, and social and behavioral sciences. ${ }^{11}$ In engineering, the average annual increase in applications was $10.2 \%$ from fall 2005 to fall $2010 .{ }^{12}$ Contrasted with applications, enrollments in engineering showed $7.4 \%$ average annual gains from fall 2009 to fall $2010 .{ }^{13}$ The long term growth projections are in striking contrast to the recent decline (although it is acknowledged that the decline is rather small overall).

The NCES Projections through 2020 forecast a significant growth in graduate degrees.

Table 1: NCES Projections of Growth in Graduate Degrees through 2020 ${ }^{14}$

\begin{tabular}{|l|l|l|l|}
\hline Degree & $2008-09$ Actual & $2020-21$ Projected & \% change \\
\hline Master's & 656,784 & 865,000 & $32 \%$ \\
\hline Doctoral & 67,716 & 106,100 & $57 \%$ \\
\hline First Professional & 92,004 & 119,200 & $30 \%$ \\
\hline
\end{tabular}

Overall, the long term projections for growth in graduate education are positive, and reflect a growth in graduate enrollments through 2020.

\section{A Note on Gender Balance and Demographics in Graduate Programs}

Women are expected to continue to dominate graduate enrollments overall. From 2009-2020, the gender gap is expected to widen, with women increasing to make up 59\% of all postsecondary students (up from $57.1 \%$ currently). ${ }^{15}$

Women dominated graduate enrollments in 2010, with men as $40 \%$ of all graduate students, and women earning the majority of doctoral degrees (for the second year in a row). ${ }^{16}$ Although women are currently outpacing men in graduate enrollment overall, women comprise just 23.7\% of the first-time enrollments in engineering graduate programs. ${ }^{17}$ According to the CGS report, for fall 2010, 24\% of first time enrollments were at the doctoral level, with $76 \%$ at the master's or other level. (In Engineering, 55\% of the total enrollments were US citizens and permanent residents, and $45 \%$ were temporary residents. ${ }^{18}$ ) So despite the predominance of women in graduate programs overall, there is still work to be done to bring gender balance to the engineering graduate programs.

\section{Trend 2: “The Bubble” and Accountability: Cost (Affordability) and Assessment}

A sense of the debate ongoing within and about higher education can be gained from such articles as that by Peter Brooks in the New York Review of Books, "Our Universities: How Bad? How Good?”19 In that article Mr. Brooks’ review includes Academically Adrift: Limited Learning on College Campuses by Arum and Roksa; Higher Education? How Colleges Are Wasting Our Money and Failing Our Kids-And What We Can Do About It, by Hacker and Dreifus; Crisis on Campus: A Bold Plan for Reforming Our Colleges and Universities, by Taylor; and Not for Profit: Why Democracy Needs the Humanities by Nussbaum. Another article that reflects the ongoing debates includes "Wanted: Better Employees" by Jeff Selingo, published in the Chronicle of Higher Education on December 12, 2011. Just a review of the 
titles of these books and articles gives a sense of the current temperature of public opinion on higher education.

A review of recent articles in the popular press and in some books recently published about higher education reveals the topics of accountability (a secondary education concept in No Child Left Behind that is extending to higher education); the "bubble" in higher education -some have suggested that the cost of education has tripled since $1980^{20}$-- (the issues of access and affordability); public funding (according to some commentators, declining state appropriations and funding of student loan programs for an indolent faculty too engaged in research to care about undergraduate education); and an overall concern with whether we are preparing graduates with skills which will make them employable (since they will need marketable skills, the commentators say, to pay off the staggering student loans). Reform suggestions abound, many of them touched upon by Brooks in the New York Review of Books article cited above: abolish tenure, an increasingly rare commodity in a university landscape dominated by adjunct and parttime faculty; abolish top heavy administration with corporate-like paychecks attached; increase retention and attainment; increase rigor (which might decrease attainment); drop the costs, which might not be realistic in the face of declining state support. Traditional university models are challenged by brand new for profits and the online delivery of education, which have attracted students and also regulators' attention.

Several of these issues are related to cost — the cost of operating a university and the rising costs to students. Facing challenges to become more "efficient" in the face of declining state support for publicly funded schools, joined with tuition caps for some state-assisted schools, universities are being squeezed from both sides of the budget issue. Even so, many universities seek additional enrollments to support their finances. Despite the squeeze, many students and their families find it difficult if not impossible to fund a college education that extends four to six or more years for an undergraduate degree, let alone the cost of professional or graduate school.

This creates another issue, as funding for higher education is increasingly tied to retention and completion, not admissions. However, one can't retain students that are not admitted in the first place. A certain level of admission has to exist to fund the necessary level of attainment. To give some context for this discussion, the NCES reports that in 2007-08, the average total price for tuition, books and living expenses for one year of full time graduate education was $\$ 34,600$ for a master's degree program; $\$ 39,700$ for a doctoral program; and $\$ 46,500$ for a firstprofessional degree program. ${ }^{21}$

One issue that affects access and affordability for graduate schools, apart from the cost of graduate tuition and related expenses, is the fact that students may come into grad school with significant debt burdens. According to at least one source, about $60 \%$ of students graduating from four-year colleges have taken out student loans ${ }^{22}$, and the average student loan debt is approximately $\$ 25,000$. The NCES reports a lower figure: $56 \%$ of all students had student loans (for 08-09), ${ }^{23}$ with a lower total average student loan debt, but the Pew Research Surveys cite a balance of $\$ 23,000$. Further, it has been found that some of the debt burden bachelor's degree graduates have is from non-traditional (not federally supported) student loans. Students in recent years also increasingly use non-governmental sources to support themselves in college, and increasingly use credit cards to support themselves and pay educational expenses. ${ }^{24}$ This means 
that the debt burden students carry may or may not be deferrable and may also be at a much higher interest level than assumed. Arum and Roksa point out that at least some students borrow more money than is strictly necessary to enjoy the full "college experience".

Although some students may return for graduate education having already repaid their student loans, it is reasonable to assume that at least a portion of the graduate students come in very shortly after graduation with a bachelor's degree. Since students may come into graduate school with significant debt already owing, the cost of graduate school becomes increasingly important to incoming graduate students. Recent news articles have focused on the attention-getting stories of graduate and professional students with mind-boggling debt. While we may hope these are the exception, the reality is that the cost of graduate school for many students comes at an added debt level upon an already significant load. The issue of cost and debt burden is inevitably linked to the issue of what students are paying for, and which generally refers to the discussion of accountability and the job market.

\section{Assessment and Accountability}

The issue of what students get for all this money accompanies the discussion of the cost of higher education (including graduate education). While some of the focus is on job placement, the issues of accountability and assessment also include such issues as faculty workload and whether higher education should focus on teaching or research, as mentioned in the Brooks article cited above. Recent news reports show an interest in exploring what faculty actually do for their often publicly supported salaries, and efforts to assess and "justify" salaries have been featured in the news recently. Texas A\& M University has been widely discussed in the media for efforts to track and quantify what faculty members do to earn their salaries, for example. ${ }^{25}$

There are efforts at all levels to look at what educators do and gauge their effectiveness; what do the students learn? What can they do or what do they know when they graduate? Can they pay for their education when they graduate? These questions put pressure on the graduate programs to document what their graduates' career paths look like, and to discover (and perhaps disclose) placement data for graduates.

\section{Trend 3: Job Preparation -What jobs do we prepare graduates for?}

The question raised above-_what jobs are we preparing our graduate students for?”- has in some ways become the center of the discussion. If students ultimately graduate (with or without a substantial amount of debt), do they get jobs which will help them repay the cost of their education? Is education still worth the investment?

Much of the discussion for graduate students now centers on the formerly "alternative" career track, which is now the mainstream, that is, we are not now preparing future faculty. There was some thought that graduate education was primarily preparing future faculty, especially faculty members at what were identified as R1 or research intensive universities. The decline of full time tenured or tenure-track faculty has made that career path the exception rather than the rule: faculty preparation has become the "alternative". So what are we preparing graduates for? In professional schools, the answer is probably clearer; for other programs, universities are being 
asked to identify career paths and perhaps even to show placement data (even for graduate programs) as part of the accountability and assessment process listed above. According to Arum and Roksa, recent government reports show a decline in full time instructional faculty from $78 \%$ in 1970 to $52 \%$ in $2005 .{ }^{26}$ This has a serious impact on graduate education, as the faculty members who work with graduate students are usually tenured faculty. The decline in the numbers of tenured faculty pushes more of the work load onto the remaining faculty, so that the faculty members are assuming increasing workloads in working with graduate students. The decline of tenured and tenure track positions then leaves fewer job openings for traditional graduates of doctoral programs.

There has also been an increasing focus on Professional Master's and Doctoral Degreesdegrees which prepare graduates for careers in business, industry or government. Increasingly these are not thesis-based degrees (although they may be), but have a significant component of "practical skills" or business skills for their graduates in leadership, finance, project management, etc.

Part of the discussion also focusses on whether the graduates of university programs, whether undergraduate or graduate level, are prepared for the world of work. Many point to the criticisms of employers on the job-readiness of graduates as evidence that college education is not effective. There is a significant debate on whether the purpose of college is to prepare "jobready" graduates, and this leads in part to the next trend reviewed.

\section{Trend 4: Rigor-Preparation for Graduate Studies}

Some use recent survey results to argue that college does not prepare graduates properly (which relates again to the issue of what college grads get for their money). For undergraduates, there have been some findings by Arum and Roksa which have sparked a heated discussion on their validity, meaning and impact. Although the Arum and Roksa study is focused on undergraduates, the findings will bear on graduate education, since the students which come into the graduate programs of study are products of this undergraduate milieu. The work of Arum and Roksa is reviewed here for the issues it raises on the future of education — the opinions of those critical of their work are not reviewed here.

Academically Adrift examined the characteristics and performance of 2,322 students in college. The researchers used the Collegiate Learning Assessment (CLA) test to measure the extent to which students learned in their first two years of college, as a proxy for measuring improvement in critical thinking, complex reasoning and writing (with those skills standing in for what students are supposed to be learning in college). Arum and Roksa concluded that many students are only minimally improving their performance in these areas at the end of their first two years in college. "From their freshman entrance to the end of their sophomore year, students in our sample on average have improved these skills, as measured by the CLA, by only 0.18 standard deviation", which translates to a 7 percentile point gain. In the sample of approximately 2300 students, they found that there were no statistically significant gains in critical thinking, complex reasoning and writing skills for at least $45 \%$ of the students in the study. ${ }^{27}$ 
In a similar fashion, the bachelor's degree is treated as a proxy for a certain level of education and ability in the work world (and also for graduate education). The result may be that the students of this four-to-six year process come into graduate education without the background and preparation that graduate faculty may assume they have. Instead of four years of preparation, the students may instead arrive with far less experience at the correct level, or may appear in graduate programs with an undergraduate degree but without substantial preparation at all for graduate work, which typically involves a greater focus on research, reading and writing (something students in Academically Adrift did not do and may have worked to avoid). Arum and Roksa's findings specifically target the reading and writing experiences of the students surveyed in the study.

Half of the seniors surveyed in the Arum and Roksa work report that they have not written a paper longer than 20 pages in their last year of college. ${ }^{28}$ Students report that they spend the majority of their out of class time on social and leisure activities, not studying. ${ }^{29}$ According to their results, the goal for students is to have fun, with academics as the excuse for the endeavor. Students are not spending a great deal of time outside the classroom on their coursework: on average, they report spending only 12 hours per week studying. ${ }^{30}$

Fifty percent of students in the Arum and Roksa sample reported that they had not taken a single course during the prior semester that required more than twenty pages of writing, and one-third had not taken a course that required even forty pages of reading per week. Combining these two indicators, a quarter of the students in the sample had not taken any courses which required either of these two requirements, and only $42 \%$ had experienced both a reading and writing requirement of this character in the prior semester. ${ }^{31}$

According to Arum and Roksa, students are choosing courses to minimize the work needed in their studies, which minimizes the personal commitment needed to get high grades. Students concentrating in science and mathematics reported studying on average 14.7 hours per week, those who concentrated in business reported 9.6 hours per week, those concentrating in education and social work 10.6 hours per week, and those concentrating in communications 10.5 hours per week. Students reported spending on average 15 hours per week attending classes and labs (and an average of 43 hours per week on social and leisure activities).

Of particular interest to engineering, students with course concentrations in engineering and computer sciences less frequently reported taking courses with either the reading or the writing requirement, and thus were more likely to report having experienced neither one.

Two categories of majors stand out-social science/humanities and science/mathematics. Students in those fields of study have higher predicted CLA scores than students in other college majors. (Engineering and Computer Science is a separate category and fell in the midrange between Business on the low end and Science/math on the higher end.

Arum and Roksa do point out that students who expect to go to graduate school or professional school may study harder, in anticipation of needing critical thinking and writing skills to continue their education. However, the data they report is concerning for those in graduate education. 


\section{Certifications, Credentialism and "Badges"}

Arum and Roksa refer to the phenomenon of "Credentialism" - where the focus on the "piece of paper", not what it represents. A degree is a hoop which must be jumped through in order to get a good job. "We have credentialism to thank for aversion to learning that, to a great extent, lies at the heart of our educational system." ${ }^{32}$ Students are looking for the easiest and most convenient way to obtain the credential that will be valuable in the job market. ${ }^{33}$ The degree is the important thing, not the skills and knowledge it represents; if the degree has the same value, regardless of the effort which has gone into it, why do more work to obtain the piece of paper? This brings the topic back to job market and job performance-if employers use the bachelor's degree as a proxy for job preparation and training (whether they should or not), the fact that students are looking for the easiest way to obtain the degree as the ticket to a good-paying or rewarding job is bound to result in disappointment for the employers. The graduates they hire will have the credential, but its value will have been reduced. Employers may need to use a different method of screening employees (testing for skills, not relying on the grant of a degree). Likewise, graduate programs may regard the undergraduate diploma as an indicator that students bring a certain level of academic experience with them, and the students may have minimized their academic experiences of intensive reading and writing, both of which are typically required for graduate success.

The credentialism issue touches on another area which may have impact on graduate education. Currently MIT has plans to offer students the opportunity to take online tests and earn "certificates". Others have proposed that students get badges for certain achievements, such as viewing videos and passing tests. ${ }^{34}$ As those badges accumulate, students may earn other credentials. Will this be a viable option to replace the college degree? Will employers accept this notion? If so, will the college degree (including the graduate degree) decline as students seek more particular and specialized skills which can be obtained in a less costly and more convenient environment?

\section{The Implications for Engineering and Technology}

As shown in this short review of just some of the trends and recent information, there are many factors which bear upon the future of education, and many of these factors influence each other to such a degree that it is difficult to disentangle them. Factors which graduate faculty will have to consider are the projected increases in enrollments, contrasted with the declining market for faculty, and an interest in alternative credentials rather than degrees. What careers are we preparing graduate students for? Are we providing the right kind of skills? Do we need to look at undergraduate education to make sure that students are getting the right kind of preparation for graduate school? Do we need to incorporate more reading and especially writing in undergraduate programs to prepare them for success at the graduate level? What is the role of distance education? Can students afford graduate school? How can we track the success of our graduates? Some of the current research raises more questions than it answers, but it certainly promises to be an interesting decade to come in graduate education. 
${ }^{1}$ Arum, R. and Roksa, J. (2011). Academically Adrift: Limited Learning on College Campuses. Chicago, IL: University of Chicago Press

${ }^{2}$ Arum, R. and Roksa, J. (2011). Academically Adrift: Limited Learning on College Campuses. Chicago, IL: University of Chicago Press

${ }^{3}$ Council of Graduate Schools, (September, 2011). Graduate Enrollment and Degrees: 2000-2010

${ }^{4}$ Gazing Into Higher Ed's Future, Inside Higher Ed (September 22, 2011)

${ }^{5}$ Council of Graduate Schools, (September, 2011). Graduate Enrollment and Degrees: 2000-2010

${ }^{6}$ June, Audrey Williams (September 22, 2011) New Graduate-Student Enrollment Dips for First Time in 7 Years, The Chronicle of Higher Education, reporting the Council of Graduate Schools numbers.

${ }^{7}$ June, Audrey Williams, cited above.

${ }^{8}$ CGS report, p. 55

${ }^{9}$ CGS report, p. 51

${ }^{10}$ June, Audrey Williams (October 2, 2011). The Chronicle of Higher Education.

${ }^{11}$ CGS report, $p$ viii

${ }^{12}$ CGS report, p. 52

${ }^{13}$ CGS report. P. 54

${ }^{14}$ As reported in Insider Higher Ed September 22, 2011

${ }^{15}$ Gazing Into Higher Ed's Future, Inside Higher Ed cited above.

${ }^{16}$ June, Audrey Williams, cited above in September 2011.

${ }^{17}$ CGS Report, p. 7

${ }^{18}$ CGS Report, p. 14

${ }^{19}$ Brooks, Peter. (March 24, 2011) Our Universities: How Bad? How Good? New York Review of Books.

${ }^{20}$ Pew Research Center surveys on Is College Worth It? at http://www.pewsocialtrends.org/2011/05/15/is-collegeworth-it/2/

${ }^{21}$ National Center for Education Statistics (NCES) at http://nces.ed.gov/programs/coe/indicator_gsn.asp

${ }^{22}$ Arum and Roksa, Academically Adrift, cited above.

${ }^{23}$ NCES, http://nces.ed.gov/programs/coe/indicator_tld.asp

${ }^{24}$ Arum and Roksa, cited above.

${ }^{25}$ Mangan, K. (September 15, 2010) Texas A\&M’s Bottom-Line Ratings of Professors Find that Most Are CostEffective, Chronicle of Higher Education, http://chronicle.com/article/Texas-A-Ms-Bottom-Line/124451/

${ }^{26}$ Arum and Roksa, cited above.

${ }^{27}$ Arum and Roksa, cited above.

${ }^{28}$ Arum and Roksa, cited above.

${ }^{29}$ Arum and Roksa, cited above, in Chapter 3.

${ }^{30}$ Arum and Roksa, cited above.

${ }^{31}$ Arum and Roksa, cited above.

${ }^{32}$ Arum and Roksa, citing David Labaree.

${ }^{33}$ Arum and Roksa, cited above.

${ }^{34}$ Young, J. (January 8, 2012) “Badges” Earned Online Pose Challenge to Traditional College Diplomas, Chronicle of Higher Education, http://chronicle.com/article/Badges-Earned-Online-

Pose/130241/?sid=pm\&utm_source=pm\&utm_medium=en 